\title{
Prevalence and Factors Associated with Anemia in Pregnancy among Women Receiving Antenatal Care at the West Gonja District Hospital of Northern
}

\section{Ghana}

\author{
Martin Mumuni Danaah Malick ${ }^{1}$, Aloysius Maalekuu ${ }^{2}$, Odalys Hernandez Rivera ${ }^{3}$ \\ ${ }^{1}$ University for Development Studies, School of Medicine and Health Sciences, Department of Pharmacy \\ ${ }^{2}$ University for Development Studies, School of Medicine and Health Sciences, Department of Community \\ Health and Family Medicine \\ ${ }^{3}$ University for Development Studies, School of Medicine and Health Sciences, Department of internal Medicine \\ and Therapeutics
}

Corresponding Author: Martin Mumuni Danaah Malick; mdanaah@uds.edu.gh

Received 19 June 2020;

Accepted 18 July 2020;

Published 01 August 2020

\begin{abstract}
Background: Anemia in pregnancy is a major public health problem especially in Low and Middle-income countries (LMIC) including Ghana and is defined by the World Health Organization (WHO) as being present when the hemoglobin concentration in the peripheral blood is $11 \mathrm{~g} / \mathrm{dl}$ or less. In most African countries anemia in pregnancy occurs if the hemoglobin concentration falls below $10 \mathrm{~g} / \mathrm{dl}$. Pregnant women are at a higher risk of developing anemia due to several factors such as hemodilution, nutritional factors, multiple gestation, socio-economic status and malaria infestation. Anemia in pregnancy is an important cause of maternal mortality and affects half of pregnant women worldwide; with 56\% of West African pregnant women being anemic. The objective of this study is to assess the prevalence and identify the risk factors associated with anemia among pregnant women receiving antenatal care at the West Gonja Hospital(WGH) Methods: A cross-sectional was conducted with 136 pregnant women receiving antenatal care at the WGH between January 2017 to February 2018. Random sampling was used to select participants and data was collected using a structured questionnaire. Data was analyzed using the SPSS Version 24.0. Results: A total 71(52.2\%) of the study population were anemic, while $65(47.8 \%)$ were not anemic. 20(74.1\%) of the 27 pregnant housewives were anemic, while $11(64.7 \%)$ of the pregnant farmers were anemic. 27 (96.4\%) of the 28 pregnant women who took their iron/folate supplement only some few days were anemic. $12(100 \%)$ of the 12 participants who took their iron/folate supplement a few times a week were anemic. $4(80 \%)$ of the 5 participants who never took their iron/folate supplement were anemic. $21(70 \%)$ of those who did not sleep under ITN were anemic. 33 (84.6\%) of the 39 patients who were diagnosed with malaria were also anemic. $28(87.5 \%)$ of the 32 participants who took only 2 meals a day were anemic. 27 (79.4\%) of the 34 patients who took liver, beef, chicken and fish only twice weekly were anemic. 15 (88.2\%) of the 17 patients who drank tea some days in a week were anemic. Conclusion: Although most of the pregnant women were adequately educated on the most relevant aspects of anemia in pregnancy, more than half of them were still anemic. Anemia was more prevalent among pregnant uneducated housewives with poor nutritional habits. All the pregnant sickle cell disease patients as well as those diagnosed with malaria were also anemic.
\end{abstract}

Keywords: Prevalence, Anemia in Pregnancy, Risk factors, socio-demographics, Nutritional status.

\section{Introduction}

Anemia is defined as a decrease in the oxygen carrying capacity of blood due to a decrease in blood volume, a decrease in the total number of red blood cells, a decreased concentration of hemoglobin or a combination of any of the three. The World Health Organization (WHO) defines anemia in pregnancy as being present when the hemoglobin concentration in the peripheral blood is $11 \mathrm{~g} / \mathrm{dl}$ or less ${ }^{[1]}$. In most African countries anemia in pregnancy occurs if the hemoglobin concentration falls below $10 \mathrm{~g} / \mathrm{dl}{ }^{[2]}$. Pregnant women are generally at an increased risk of developing anemia due to scientifically determined factors such as nutritional status, grand multiparity, multiple gestation, low socio-economic status, inadequate child spacing, chronic blood loss, hookworm infestation, hemoglobinopathies, malaria infestation and hemodilution ${ }^{[3]}$. 
The symptoms of anemia are usually non-specific and vague but generally include fatigue, weakness, dizziness, breathlessness, headache, and when severe enough, there may be hypotension, dyspnea, palpitations, lethargy and paresthesia ${ }^{[4]}$, Although Anemia is a condition that can be easily prevented, it constitute a major cause of mortality and morbidity among pregnant women; and accounts for about $20 \%$ of maternal deaths worldwide ${ }^{[5]}$.

About $24.8 \%$ of the world population is affected by anemia representing 1.62 billion people ${ }^{[6]}$. Anemia in pregnancy is a major public health problem especially in Low and Middle-Income Countries such as Ghana; and It has been estimated that $41.8 \%$ of pregnant women worldwide are anemic. In developing countries, the prevalence of anemia in pregnancy is $60.0 \%$ of which about $7.0 \%$ of these women are severely anemic ${ }^{[7]}$. In Africa $57.1 \%$ of pregnant women are anemic ${ }^{[8]}$. Sub-Saharan Africa is the most affected region, with prevalence of anemia estimated to be 17.2 million among pregnant women, which is about $30 \%$ of total global cases ${ }^{[9]}$.

Despite the fact that the Government of Ghana through the Ghana Health Services has implemented several policies and interventions to reduce the prevalence of Anemia in Pregnancy; the country still has a prevalence rate of about $62.4 \%$, with higher prevalence rates being recorded in the rural areas ${ }^{[10]}$. To the best knowledge of the researchers, the prevalence of anemia in pregnancy specific for West Gonja District of the Savannah Region of Ghana has not yet been studied. The purpose of this study was to determine the prevalence and identify the risk factors associated with anemia in pregnancy in the West Gonja District

\section{Materials and Methods}

This was a cross-sectional study conducted with 136 pregnant women receiving antenatal care at the west gonja District hospital between 28th January 2018 to 15th February, 2019. Study participants were randomly selected as they were waiting to receive care at the antenatal care unit. To avoid data duplication, a unique code was assigned to each study and recorded on the questionnaire to help identify them. An interview was conducted using a structured questionnaire to obtain data about the sociodemographic characteristics, obstetric history, antenatal visits, iron and folic acid supplementation, health conditions during the pregnancy, nutritional assessment and finally, knowledge of anemia assessed by the mother's ability to correctly name at least one symptom, two causes, and two preventive measures of anemia. Hemoglobin levels were obtained from their antenatal records. Data was analyzed through the IBM Statistical Package for Social Sciences(SPSS) version 24.0 to obtain frequencies and cross tables for all relevant Variables. Univariate and multivariate analysis were used to explore associations between the individual factors (independent variables) and the outcome variable. Chi square was used as the statistical test to test associations between the independent variables and the outcome variables using regression analysis. Each study participant gave their written informed consent to participate in the study and were assured of full confidentiality with their personal health related information. Written Permission to conduct the study was fully granted by the hospital management team and since the study did not involve any medical intervention nor did it pose any health risk on respondents, there was no need for an ethical clearance from the district health directorate.

\section{Inclusion and Exclusion Criteria}

Only pregnant women who had evidence of recently (during the study period) determined hemoglobin level documented and were compliant with their scheduled antenatal care appointments (based on details from their antenatal records); were included in this study. Pregnant women who were not compliant with their scheduled antenatal care appointments as well as those who were being prepared for labor and delivery were all excluded from the study.

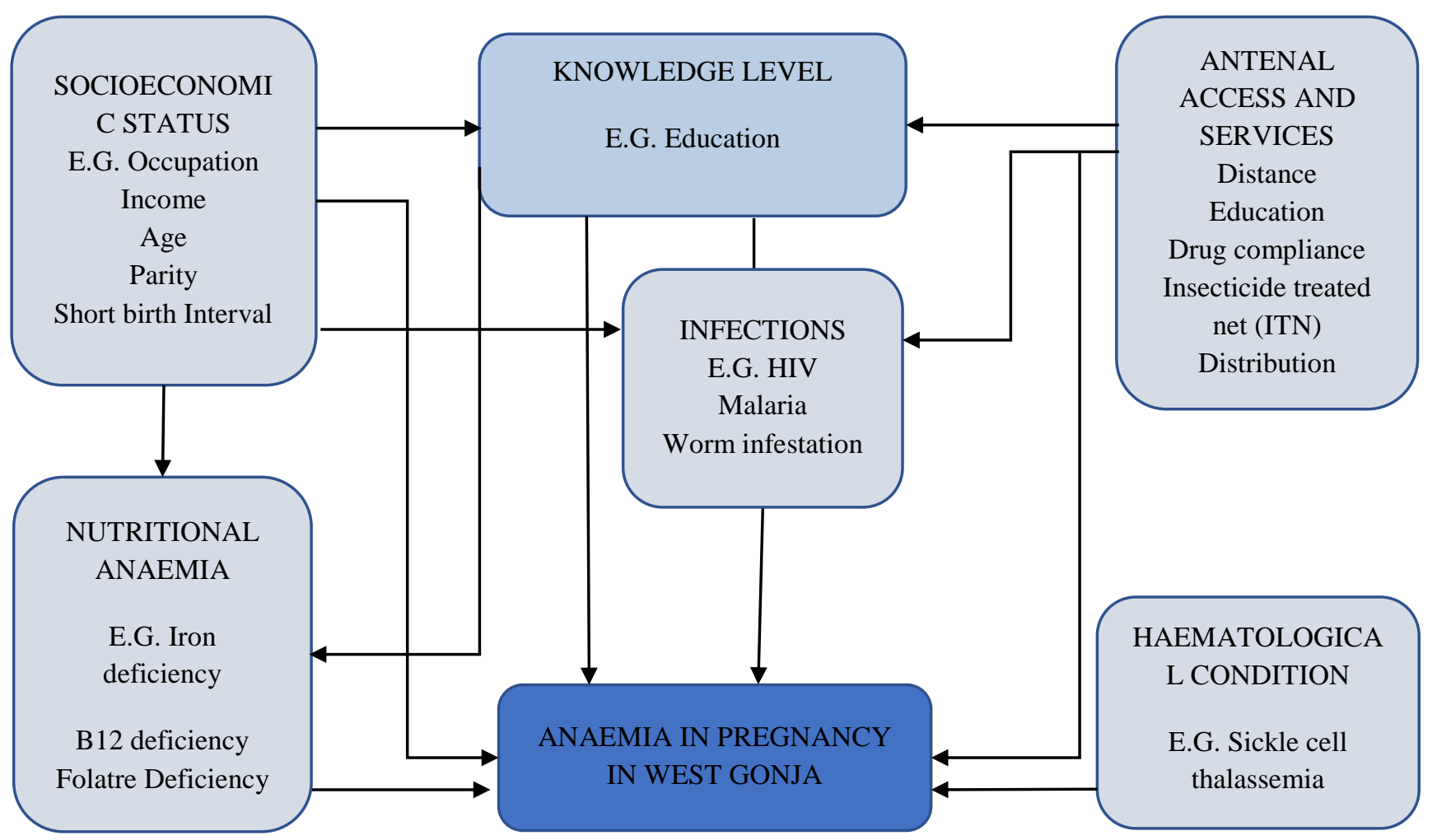

Figure 1: Conceptual Framework 


\section{Results}

1.0: Socio-demographic characteristics of study participants. The mean age range of the 136 respondents was $24-28,41(30 \%)$ and closely followed by 19-23, 38(29\%), with both age ranges representing more than $50 \%$ of the distribution. Only $8(5 \%)$ were 18 years and below, and 49 (35\%) were above 28 years. Most, 108
(79\%) of the expectant mothers were married while the remaining $28(21 \%)$ were single. $39(29 \%)$ of the respondents were traders and $9(7 \%)$ were government workers. $69(51 \%)$ of respondents were Christians while 67 (49\%) were of the Islamic faith. 57 (41\%) attained primary education, $29(21.32 \%)$ had no education, 8 $(5.88 \%)$ attained vocational training, $23(16.91 \%)$ were secondary school graduates while $19(13.97 \%)$ completed tertiary education secondary and tertiary education (Table. 1)

Table 1.0: Socio-demographic characteristics of study participants

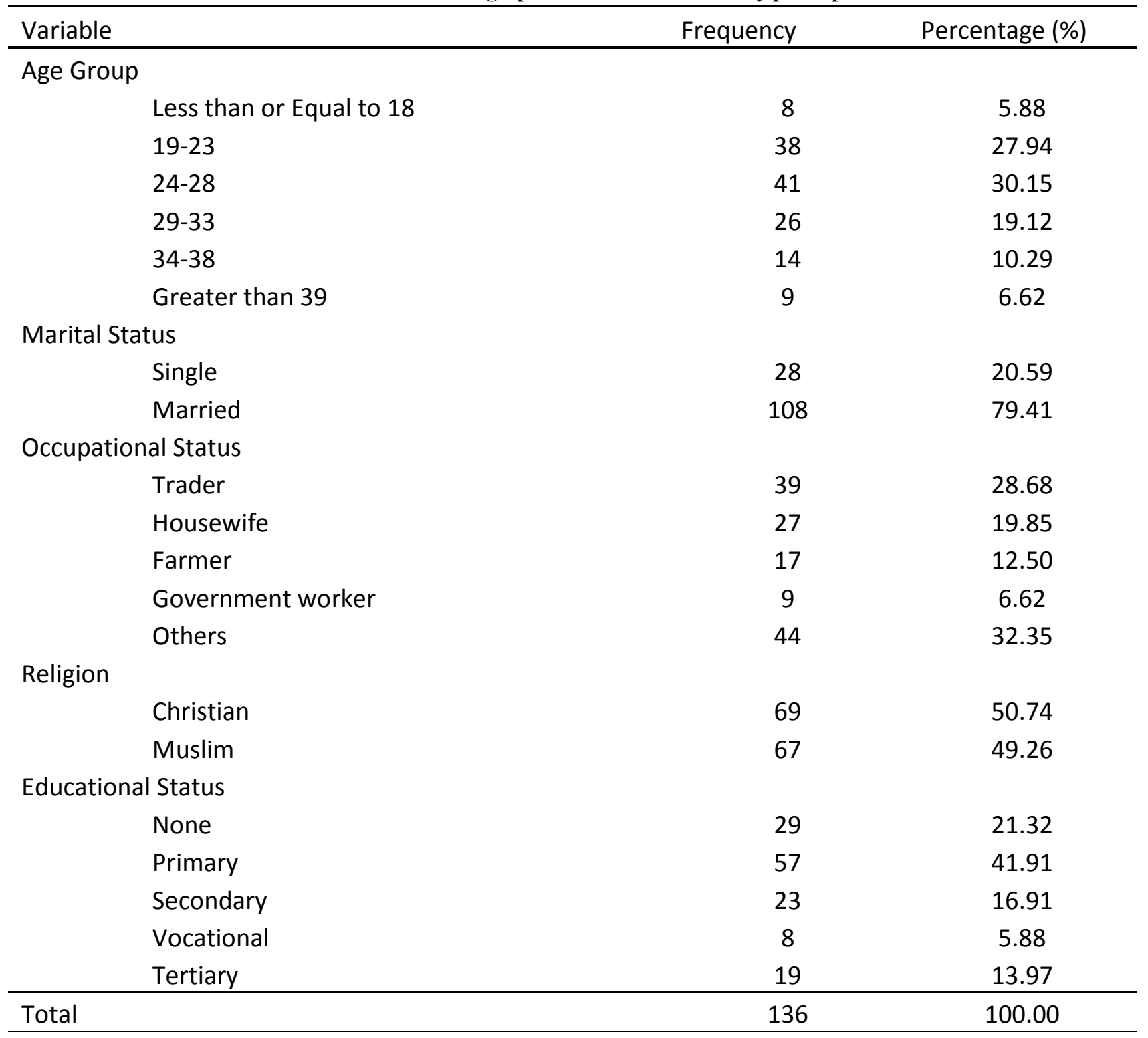

\section{1: Obstetric and Antenatal background of study participants} $43(31.6 \%)$ of expectant mothers were primigravida whiles 93 $(68.30 \%)$ were multigravida. $48(35.5 \%)$ respondents were nulliparous. $88(64.7 \%)$ respondents were multiparous of which only $3(2.1 \%)$ had more than four deliveries past 28 weeks. 62 $(45.6 \%)$ study participants had their youngest child two years ago or more while $24(17.6 \%)$ had the youngest child less than two years of age. The rest, $50(36.8 \%)$ were either nulliparous or had lost their child during their neonatal period. $65(47.8 \%)$ were in their second (2nd) trimester, $36(26.5 \%)$ in their third (3rd) trimester, and $35(25.7 \%)$ in their first (1st) trimester at the time of data collection. $99(72.8 \%)$ had their first antenatal visit in their first (1st) trimester, $36(26.5 \%)$ in their second (2nd) trimester and $0.7 \%$ (1) in their third (3rd) trimester. $38(27.9 \%)$ had never had any prior antenatal visit. $3(2.1)$ had more than 4 antenatal visits while $8(5.9 \%)$ had four (4) antenatal visits. 91 (66.9\%) were currently on iron/folate tablets supplementation, $45(33.1 \%)$ were not on any supplementation tablets. Of the 91 taking the iron/folate tablets supplementation, $69(75.82 \%)$ started in their first (1st) trimester, $21(23.07 \%)$ in their second (2nd) trimester and only $1(1.1 \%)$ started in her third (3rd) trimester. In terms of compliance with iron/folate supplementation, 52 (38.2\%) took twice daily, 39 $(28.7 \%)$ had not yet taken and $5(3.7 \%)$ had never taken though they have had more than one antenatal visit (Table. 1.1) 
Table 1.1: Obstetric and Antenatal background of study participants

\begin{tabular}{|c|c|c|c|}
\hline Variable & & Frequency & Percentage $(\%)$ \\
\hline \multicolumn{4}{|l|}{ Gravidity } \\
\hline & One (1) & 43 & 31.6 \\
\hline & Two (2) & 29 & 21.3 \\
\hline & Three (3) & 29 & 21.3 \\
\hline & Four (4) & 17 & 12.5 \\
\hline & Greater than Four $(>4)$ & 18 & 13.2 \\
\hline Variable & & Frequency & Percentage $(\%)$ \\
\hline \multicolumn{4}{|l|}{ Parity } \\
\hline & None & 48 & 35.3 \\
\hline & One (1) & 33 & 24.3 \\
\hline & Two (2) & 22 & 16.2 \\
\hline & Three (3) & 17 & 12.5 \\
\hline & Four (4) & 13 & 9.6 \\
\hline & Greater than Four $(>4)$ & 3 & 2.1 \\
\hline \multicolumn{4}{|c|}{ Age of Youngest Child } \\
\hline & Less than Two $(<2)$ & 24 & 17.6 \\
\hline & Greater or equal to Two $(\geq 2)$ & 62 & 45.6 \\
\hline & None & 50 & 36.8 \\
\hline \multicolumn{4}{|c|}{ Current Gestational Age } \\
\hline & 1st Trimester & 35 & 25.7 \\
\hline & 2nd Trimester & 65 & 47.8 \\
\hline & 3rd Trimester & 36 & 26.5 \\
\hline \multicolumn{4}{|c|}{ Gestational Age at 1 st ANC visit } \\
\hline & 1st Trimester & 99 & 72.8 \\
\hline & 2nd Trimester & 36 & 26.5 \\
\hline & 3rd Trimester & 1 & 0.7 \\
\hline \multicolumn{4}{|c|}{ Number of Antenatal visits } \\
\hline & None & 38 & 27.9 \\
\hline & One (1) & 34 & 25 \\
\hline & Two (2) & 13 & 9.6 \\
\hline & Three (3) & 13 & 9.6 \\
\hline & Four (4) & 8 & 5.9 \\
\hline & Greater or equal to five $(\geq 5)$ & 30 & 22 \\
\hline \multicolumn{4}{|c|}{ Are you Currently on Iron/Folate Tablets } \\
\hline & Yes & 91 & 66.9 \\
\hline & No & 45 & 33.1 \\
\hline \multicolumn{4}{|c|}{ When did you start taking them } \\
\hline & 1st Trimester & 69 & 50.7 \\
\hline & 2nd Trimester & 21 & 15.4 \\
\hline & 3rd Trimester & 1 & 0.7 \\
\hline & None & 45 & 33.1 \\
\hline \multicolumn{4}{|c|}{ How many do you take in a week } \\
\hline & Twice Everyday & 52 & 38.2 \\
\hline & Some days & 28 & 20.6 \\
\hline & Few times a week & 12 & 8.8 \\
\hline & Never & 5 & 3.7 \\
\hline & Not yet & 39 & 28.7 \\
\hline Total & & 136 & 100 \\
\hline
\end{tabular}

\section{2: Health and Nutritional background of study participants} 106 (77.9\%) out of the 136 study participants sleep under insecticide treated nets and $30(22.1 \%)$ do not sleep under insecticide treated nets. 39 (28.7\%) were diagnosed with malaria in the past six (6) months while $97(71.3 \%)$ did not suffer from any malarial infection. only 2 (1.5\%) out of the 136 study participants were sickle cell disease positive while 134 (98.5\%) were negative. $78(57.4 \%)$ had averagely three meals a day, 32 (23.5\%) averagely had 2 meals a day and $26(19.1 \%)$ had averagely more than three (>3) meals a day. For the weekly intake of heme containing foods such as liver, beef, etc., 56 (41\%) had averagely three (3) times per week, $42(30.9 \%)$ had more than three (>3) times per week and Only $4(2.9 \%)$ had the heme containing foods once a week. Regarding the weekly intake of non-heme containing foods such as beans, nuts etc., 65 (47.8\%) had about three (3) times per week, 51 $(37.5 \%)$ had more than three (>3) times per week and 4 (2.9\%) had the non-heme containing foods only once a week. 77 (56.6\%) did not consume tea weekly while pregnant, $40(29.4 \%)$ consumed it a few days a week (about <3 days), 17 (12.5\%) consumed it somedays a week (less than 7 days but more than 3 days) and only $2(1.5 \%)$ consumed it every day (Table. 1.2$)$ 
Table 1.2: Health and Nutritional background of study participants

\begin{tabular}{|c|c|c|}
\hline Variable & Frequency & Percentage $(\%)$ \\
\hline \multicolumn{3}{|c|}{ Do you sleep under an Insecticide Treated Net } \\
\hline Yes & 106 & 77.9 \\
\hline No & 30 & 22.1 \\
\hline \multicolumn{3}{|c|}{ Diagnosed of malaria in the past 6 Months } \\
\hline Positive & 39 & 28.7 \\
\hline Negative & 97 & 71.3 \\
\hline \multicolumn{3}{|l|}{ Sickling Status } \\
\hline Positive & 2 & 1.5 \\
\hline Negative & 134 & 98.5 \\
\hline \multicolumn{3}{|l|}{ How many males do you take in a day } \\
\hline One $(1)$ & 0 & 0 \\
\hline Two (2) & 32 & 23.5 \\
\hline Three (3) & 78 & 57.4 \\
\hline More than Three (3) & 26 & 19.1 \\
\hline \multicolumn{3}{|c|}{ Weekly intake of Liver, Beef, Chicken, Fish } \\
\hline One $(1)$ & 4 & 2.9 \\
\hline Two (2) & 34 & 25 \\
\hline Three (3) & 56 & 41.2 \\
\hline More than Three $(>3)$ & 42 & 30.9 \\
\hline \multicolumn{3}{|c|}{ Weekly intake of Beans, Vegetables, Nuts, Fruits, Grains } \\
\hline One $(1)$ & 4 & 2.9 \\
\hline Two (2) & 16 & 11.8 \\
\hline Three (3) & 65 & 47.8 \\
\hline More than Three $(>3)$ & 51 & 37.5 \\
\hline \multicolumn{3}{|c|}{ How many times do take tea in a week } \\
\hline Everyday & 2 & 1.5 \\
\hline Somedays & 17 & 12.5 \\
\hline Few days a week & 40 & 29.4 \\
\hline None & 77 & 56.6 \\
\hline Total & 136 & 100 \\
\hline
\end{tabular}

1.3: Hemoglobin Concentration of Study Participants

$65(47.8 \%)$ of all respondents presented with normal Hemoglobin (Hb) of $\geq 11.0 \mathrm{~g} / \mathrm{dl}, 42$ (30.9\%) respondents had mild anemia with
$\mathrm{Hb}$ of 10.0-10.9 g/dl, 27 (19.9\%) were moderately anemic with $\mathrm{Hb}$ of 7.0-9.9 $\mathrm{g} / \mathrm{dl}$ and only $2(1.5 \%)$ had severe anemia $\mathrm{Hb}$ of $<7.0$ g/dl. (Table. 1.3 /Figure.1).

Table 1.3: Hemoglobin Concentration of Study Participants

\begin{tabular}{llcc}
\hline Variable & Frequency & Percentage (\%) \\
\hline Hemoglobin Level $(\mathrm{Hb})$ & & \\
& Normal $(\geq 11.0 \mathrm{~g} / \mathrm{dl})$ & 65 & 47.8 \\
& Mild $(10.0-10.9 \mathrm{~g} / \mathrm{dl})$ & 42 & 30.9 \\
& Moderate $(7.0-9.9 \mathrm{~g} / \mathrm{dl})$ & 27 & 19.9 \\
& Severe $(<7.0 \mathrm{~g} / \mathrm{dl})$ & 2 & 1.5 \\
\hline Total & & 136 & 100 \\
\hline
\end{tabular}




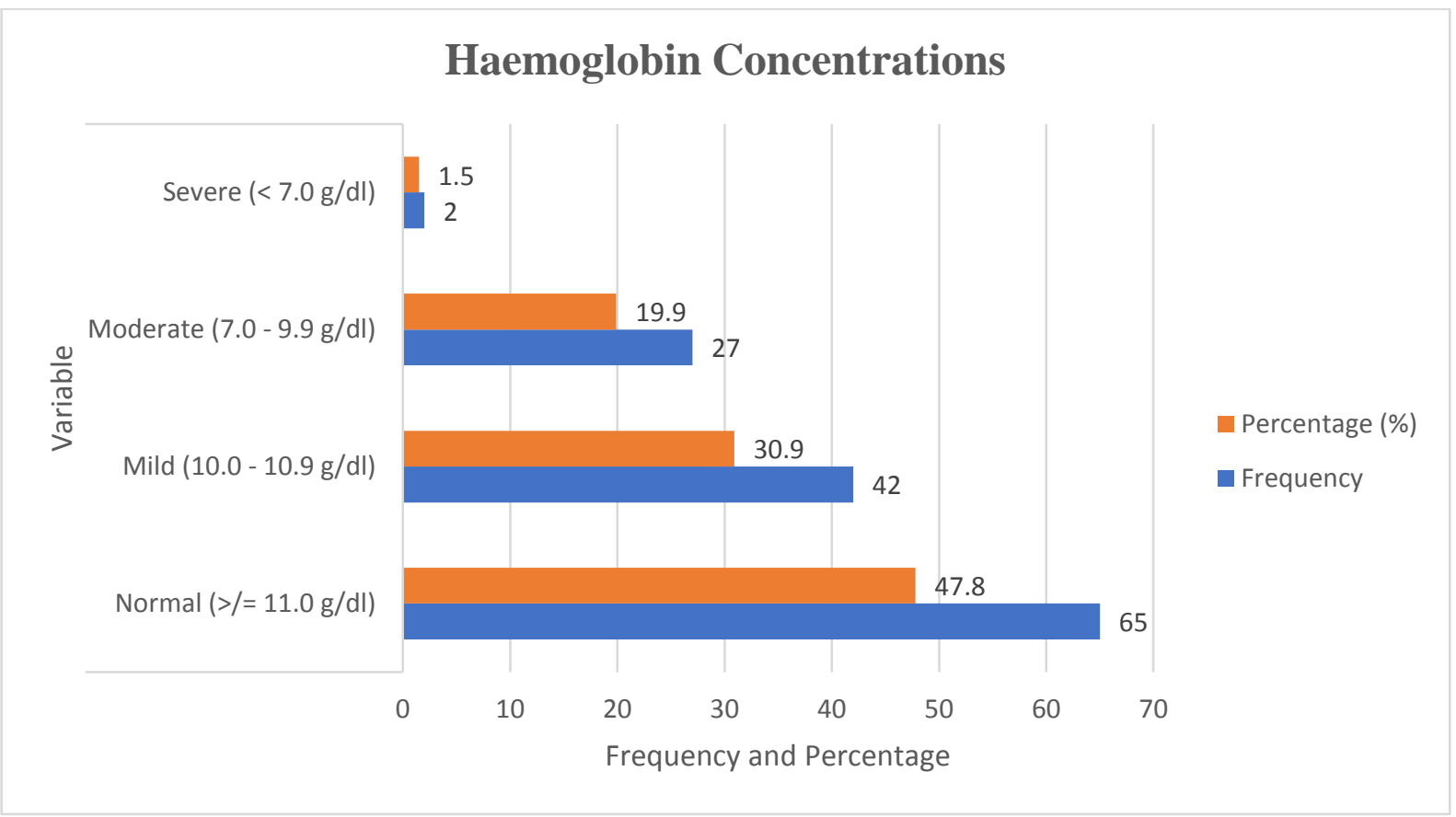

Figure 1: Hemoglobin Concentration of Study Participants

1.4: Anemia Prevalence among Study Participants
The overall prevalence of anemia within the sampled study population was $71(52.2 \%)$ as shown in (Table 1.4/Figure 2)

Table: 1.4: Anemia Prevalence among Study Participants

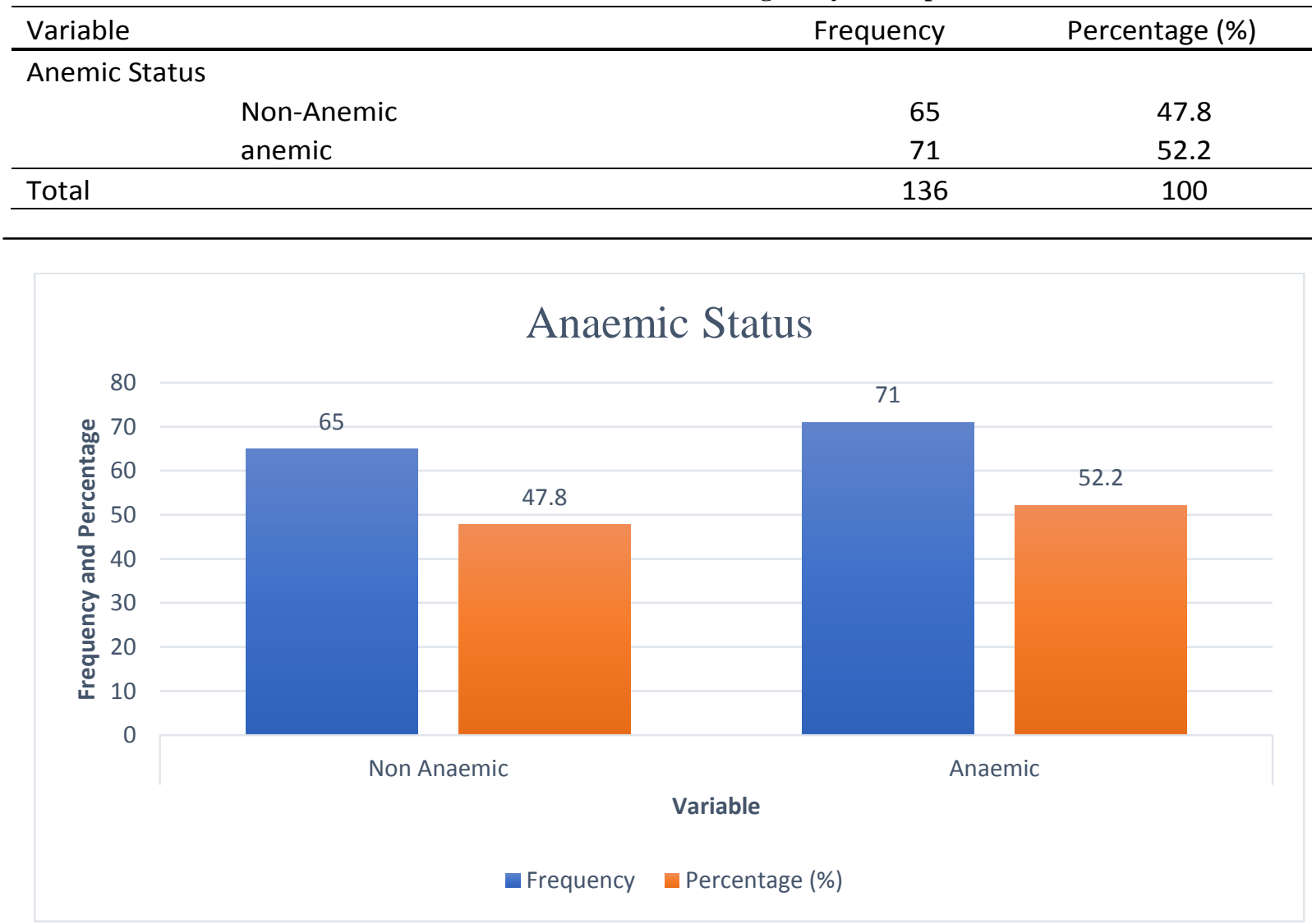

Figure 2: Anemia Prevalence among Study Participants

1.5: Distribution of Knowledge Level on Anemia in Pregnancy among Study Participants

The majority $94(69.1 \%)$ of respondents had ever been educated about anemia in pregnancy while $42(30.9 \%)$ had never been educated. Of the 94 respondents who had been educated on anemia, a significant number, 69 (50.7\%) were educated at the ANC unit, $12(8.8 \%)$ through the media, $6(4.4 \%)$ were educated by friends www.ijirms.in and family while others where educated from other sources. Concerning knowledge level of respondents on the signs/symptoms of anemia in pregnancy, $88(64.7 \%)$ scored poorly, $44(32.4 \%)$ scored fairly and $4(2.9 \%)$ scored very well.

Regarding knowledge level of respondents on the causes/ risk factors of anemia in pregnancy, majority, 74 (54.4\%) scored poorly, $49(36 \%)$ scored fairly and $13(9.6 \%)$ scored very well. In 
the area of knowledge level of respondents on the preventive

measures of anemia in pregnancy, $67(49.3 \%)$ scored poorly, 39
$(28.7 \%)$ scored very well and $30(22.1 \%)$ scored fairly. (Table 1.5/Figure. 3)

Table 1.5: Distribution of Knowledge Level on Anemia in Pregnancy among Study Participants

\begin{tabular}{|c|c|c|}
\hline Variable & Frequency & Percentage (\%) \\
\hline \multicolumn{3}{|l|}{ Have you Ever been educated on Anemia } \\
\hline Yes & 94 & 69.1 \\
\hline No & 42 & 30.9 \\
\hline \multicolumn{3}{|l|}{ Source of Information } \\
\hline ANC & 69 & 50.7 \\
\hline Media & 12 & 8.8 \\
\hline Friends & 3 & 2.2 \\
\hline Family & 3 & 2.2 \\
\hline Others & 7 & 5.1 \\
\hline None & 42 & 30.9 \\
\hline \multicolumn{3}{|c|}{ What do you thing are the signs/ symptoms of Anemia } \\
\hline Good Knowledge & 4 & 2.9 \\
\hline Fair Knowledge & 44 & 32.4 \\
\hline Poor Knowledge & 88 & 64.7 \\
\hline \multicolumn{3}{|c|}{ What do you think are the causes/risk factors of Anemia } \\
\hline Good Knowledge & 13 & 9.6 \\
\hline Fair Knowledge & 49 & 36 \\
\hline Poor Knowledge & 74 & 54.4 \\
\hline \multicolumn{3}{|l|}{ What preventive measures do you know } \\
\hline Good Knowledge & 39 & 28.7 \\
\hline Fair Knowledge & 30 & 22.1 \\
\hline Poor Knowledge & 67 & 49.3 \\
\hline Total & 136 & 100 \\
\hline
\end{tabular}

\section{Knowledge Level on Anaemia in Pregnancy}

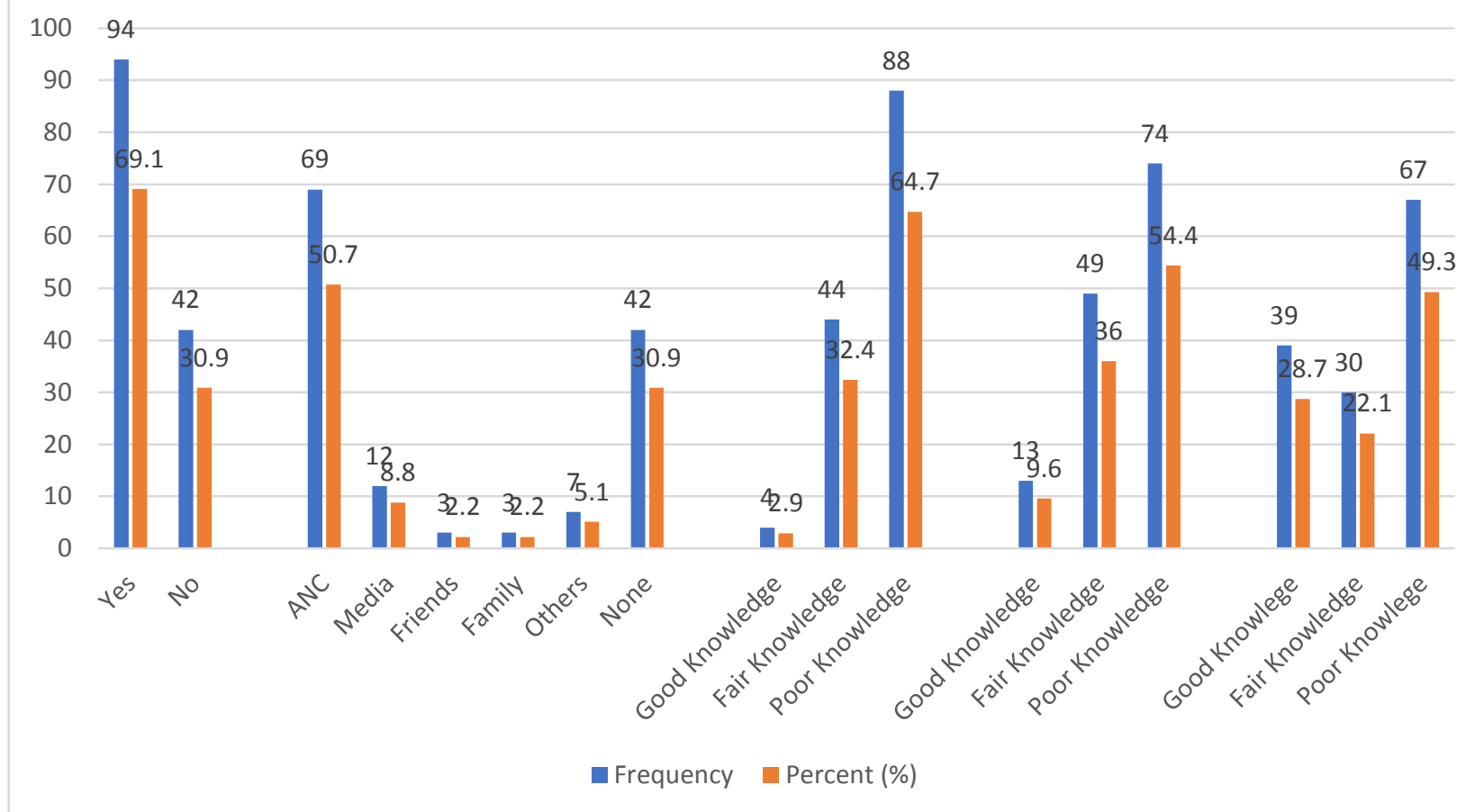

Figure 3: Distribution of Knowledge Level on Anemia in Pregnancy among Study Participants 
1.6: Distribution of Anemia by Knowledge Level about Anemia in Pregnancy.

A Chi-Square Test of independence was run to determine whether there is an association between the anemic status of the study participants and some variables assessing the knowledge level on anemia. With a chosen significance level of 0.05 , if the p-value is less than 0.05 then the association between the two variables is statistically significant hence the null hypothesis is accepted. If the p-value is greater than 0.05 then there is no association between the two variables hence the null hypothesis is rejected. (Table. 1.6)

Table.1.6: Distribution of Anemia by Knowledge Level about Anemia in Pregnancy.

\begin{tabular}{|c|c|c|c|c|}
\hline \multirow[t]{2}{*}{ Variable } & \multicolumn{2}{|c|}{ anemic Status } & \multirow[t]{2}{*}{ Total } & \multirow{2}{*}{$\begin{array}{l}\text { Chi-Squad, } x^{2}, P- \\
\text { Value }\end{array}$} \\
\hline & Non-anemic & anemic & & \\
\hline \multicolumn{4}{|c|}{ Have you Ever been educated on Anemia } & $16.929,1,<0.001$ \\
\hline Yes & $56(59.6 \%)$ & $38(40.4 \%)$ & 94 & \\
\hline No & $9(21.4 \%)$ & $33(78.6 \%)$ & 42 & \\
\hline \multicolumn{4}{|c|}{ Source of Information } & $20.807,5,<0.001$ \\
\hline ANC & $39(56.5 \%)$ & $30(43.5 \%)$ & 69 & \\
\hline Media & $10(83,3 \%)$ & $2(16.7 \%)$ & 12 & \\
\hline Friends & $1(33.3 \%)$ & $2(66.7 \%)$ & 3 & \\
\hline Family & $2(66.7 \%)$ & $1(33.3 \%)$ & 3 & \\
\hline Others & $4(57.1 \%)$ & $3(42.9 \%)$ & 7 & \\
\hline None & $9(21.4 \%)$ & $33(78.6 \%)$ & 42 & \\
\hline \multicolumn{4}{|c|}{ What do you thing are the signs/ symptoms of Anemia } & $26.423,2,<0.001$ \\
\hline Good Knowledge & $4(100 \%) 0$ & $0(0.0 \%)$ & 4 & \\
\hline Fair Knowledge & $33(75.0 \%)$ & $11(25.0 \%)$ & 44 & \\
\hline Poor Knowledge & $28(31.8 \%)$ & $60(68.2 \%)$ & 88 & \\
\hline \multicolumn{4}{|c|}{ What do you think are the causes/ risk factors of Anemia } & $36.120,2,<0.001$ \\
\hline Good Knowledge & $9(69.2 \%)$ & $4(30.8 \%)$ & 13 & \\
\hline Fair Knowledge & $38(77.6 \%)$ & $11(22.4 \%)$ & 49 & \\
\hline Poor Knowledge & $18(24.3 \%)$ & $56(75.7 \%)$ & 74 & \\
\hline \multicolumn{4}{|c|}{ What preventive measures do you } & $37.46,2,<0.001$ \\
\hline Good Knowledge & $32(82.1 \%)$ & 7 (17.9\%) & 39 & \\
\hline Fair Knowledge & $18(60.0 \%)$ & $12(40.0 \%)$ & 30 & \\
\hline Poor Knowledge & $15((22.4 \%)$ & $52(77.6 \%)$ & 67 & \\
\hline
\end{tabular}

\subsection{2: Distribution of Anemia by Knowledge Level on Anemia in Pregnancy among Study}

1.7: Distribution of Anemia among Study participants by their Socio-demographic characteristics

Only occupation of the respondents had a statistically significant association with their anemic status as the P-value was less than
0.05 . Hence, anemia was significantly high $20(74.1 \%)$ out of the 27 housewives and $11(64.7 \%)$ out of the 17 farmers. There was no association between anemia in pregnancy and the remaining sociodemographic variables since their $\mathrm{p}$-value was $>0.05$. (Table 1.7) 
Table 1.7: Distribution of Anemia among Study participants by their Socio-demographic characteristics

\begin{tabular}{|c|c|c|c|c|}
\hline \multirow[t]{2}{*}{ Variable } & \multicolumn{2}{|c|}{ anemic Status } & \multirow[t]{2}{*}{ Total } & \multirow{2}{*}{$\begin{array}{c}\text { Chi-Squad, } x^{2}, \text { P- } \\
\text { Value }\end{array}$} \\
\hline & Non-anemic & anemic & & \\
\hline Age Group & & & & $9.061,5,0.107$ \\
\hline Less or Equal to 18 & $2(25.00 \%)$ & $6(75.0 \%)$ & 8 & \\
\hline $19-23$ & $14(36.8 \%)$ & $24(63.2 \%)$ & 38 & \\
\hline $24-28$ & $18(43.9 \%)$ & $23(56.1 \%)$ & 41 & \\
\hline $29-33$ & $16(61.5 \%)$ & $10(38.5 \%)$ & 26 & \\
\hline $34-38$ & $10(71.40 \%)$ & $4(28.6 \%)$ & 14 & \\
\hline Greater than 39 & 5 (55.6\%) & $4(44.4 \%)$ & 9 & \\
\hline Marital Status & & & & $0.344,1,0.557$ \\
\hline Single & $12(42.9 \%)$ & $16(57.1 \%)$ & 28 & \\
\hline Married & $53(49.1 \%)$ & 55 (50.9\%) & 108 & \\
\hline Occupational Status & & & & $12.435,4,0.014$ \\
\hline Trader & 24 (61.5\%) & $15(38.5 \%)$ & 39 & \\
\hline Housewife & 7 (25.9\%) & 20 (74.1\%) & 27 & \\
\hline Farmer & $6(35.3 \%)$ & $11(64.7 \%)$ & 17 & \\
\hline Government worker & 7 (77.8\%) & $2(22.2 \%)$ & 9 & \\
\hline Others & $21(47.7 \%)$ & $23(52.3 \%)$ & 44 & \\
\hline Religion & & & & $1.077,1,0.299$ \\
\hline Christian & $36(52.2 \%)$ & $33(47.8 \%)$ & 69 & \\
\hline Muslim & $29(43.3 \%)$ & $38(56.7 \%)$ & 67 & \\
\hline Educational Status & & & & $26.085,4,<0.001$ \\
\hline None & $9(31.0 \%)$ & $20(69.0 \%)$ & 29 & \\
\hline Primary & $18(31.6 \%)$ & 39 (68.4\%) & 57 & \\
\hline Secondary & $16(69.6 \%)$ & 7 (30.4\%) & 23 & \\
\hline Vocational & 7 (87.5\%) & $1(12.5 \%)$ & 8 & \\
\hline Tertiary & $15(78.9 \%)$ & $4(21.1 \%)$ & 19 & \\
\hline
\end{tabular}

1.8: Distribution of Anemia among Study participants by their Obstetric and Antenatal background.

Only number of folate/iron intake as a variable had a statistically significant association with the anemic status of study respondent as the P-value was less than 0.05 . There were more Non-Anemics,
$45(86.5 \%)$ among the 52 that took their supplement twice daily. Also, anemia prevalence was significantly high, $4(80 \%)$ among the 5 that had never taken any iron or folate supplementation. (Table. 1.8) 
Table 1.8: Distribution of Anemia among Study participants by their Obstetric and Antenatal background

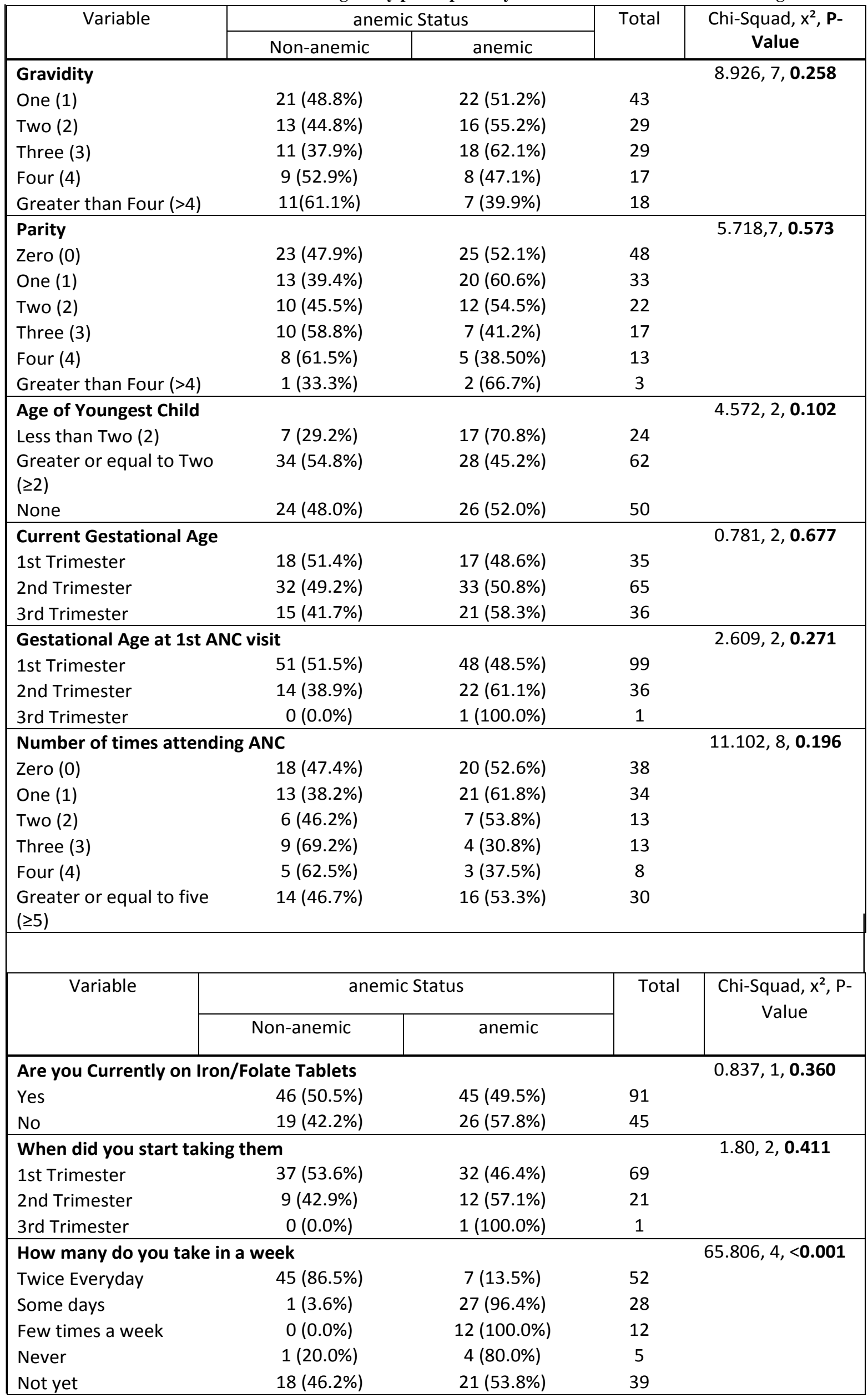


1.9: Distribution of Anemia among Study participants by their Health and Nutritional background

Anemia was significantly high in $21(70 \%)$ of the 30 respondents who did not sleep under insecticide treated nets. Also, non-anemic respondents were significantly high in $59(60.8 \%)$ of the 97 who were not diagnosed with malaria in the last six (6) months. (Table.1.9)

Table 1.9: Distribution of Anemia among Study participants by their Health and Nutritional background

\begin{tabular}{|c|c|c|c|c|}
\hline \multirow[t]{2}{*}{ Variable } & \multicolumn{2}{|c|}{ Anaemic Status } & \multirow[t]{2}{*}{ Total } & \multirow{2}{*}{$\begin{array}{c}\text { Chi-Squad, } x^{2}, p- \\
\text { Value }\end{array}$} \\
\hline & Non Anaem ic & Anaemic & & \\
\hline \multicolumn{4}{|c|}{ Do you sleep under an Insecticide Treated Net } & $4.884,1,0.027$ \\
\hline Yes & $56(52.8 \%)$ & $50(47.2 \%)$ & 106 & \\
\hline No & $9(30.0 \%)$ & $21(70.0 \%)$ & 30 & \\
\hline \multicolumn{4}{|c|}{ Diagnosed of malaria in the past 6 Months } & $23.019,1,0.000$ \\
\hline Positive & $6(15.4 \%)$ & $33(84.6 \%)$ & 39 & \\
\hline Negative & $59(60.8 \%)$ & $38(39.2 \%)$ & 97 & \\
\hline Sickling Status & & & & $1.858,1,0.173$ \\
\hline Postive & $0(0.0 \%)$ & $2(100.0 \%)$ & 2 & \\
\hline Negative & $65(48.5 \%)$ & $69(51.5 \%)$ & 134 & \\
\hline \multicolumn{4}{|c|}{ How many males do you take in a day } & $20.904,2,0.000$ \\
\hline Two(2) & $4(12.5 \%)$ & $28(87.5 \%)$ & 32 & \\
\hline Three(3) & $46(59.0 \%)$ & $32(41.0 \%)$ & 78 & \\
\hline More than Three(3) & $15(57.7 \%)$ & $11(42.3 \%)$ & 26 & \\
\hline \multicolumn{4}{|c|}{ Weekly intake of Liver, Beef, Chicken, Fish } & $20.325,3,0.000$ \\
\hline One(1) & $1(25.0 \%)$ & $3(75.0 \%)$ & 4 & \\
\hline Two(2) & $7(20.6 \%)$ & $27(79.4 \%)$ & 34 & \\
\hline Three(3) & $27(48.2 \%)$ & $29(51.8 \%)$ & 56 & \\
\hline More than Three(3) & $30(71.4 \%)$ & $12(28.6 \%)$ & 42 & \\
\hline \multicolumn{4}{|c|}{ Weekly intake of Beans, Vegetables, Nuts,Fruits, Grains } & $4.362,3,0.225$ \\
\hline One(1) & $2(50.0 \%)$ & $2(50.0 \%)$ & 4 & \\
\hline Two(2) & $6(37.5 \%)$ & $10(62.5 \%)$ & 16 & \\
\hline Three(3) & $37(56.9 \%)$ & $28(43.1 \%)$ & 65 & \\
\hline More than Three(3) & $20(39.2 \%)$ & $31(60.80 \%)$ & 51 & \\
\hline \multicolumn{4}{|c|}{ How many times do take tea in a week } & $18.902,3,0.000$ \\
\hline Everyday & $0(0.0 \%)$ & $2(100.0 \%)$ & 2 & \\
\hline Somedays & $2(11.8 \%)$ & $15(88,2 \%)$ & 17 & \\
\hline Few days a week & $15(37.5 \%)$ & $25(62.5 \%)$ & 40 & \\
\hline None & $48(62.30 \%)$ & $29(37.7 \%)$ & 77 & \\
\hline
\end{tabular}

\section{Discussion}

The overall prevalence of anemia among the pregnant women was $52.2 \%$, of which $30.9 \%$ of all the pregnant women were mildly anemic, $19.9 \%$ were moderately anemic and $1.5 \%$ were severely anemic. (Table1.4/Fig. 2). This finding is similar to the prevalence of $52 \%$ of anemia in pregnancy within the Sub-Saharan Africa ${ }^{[11]}$. The results from this study is also consistent with the finding from a study conducted in 2009 which revealed a 56- $61 \%$ prevalence of anemia in pregnancy in developing countries A report from the world Bank in 2016 revealed a 54\% of prevalence of Anemia among pregnant Ghanaian Women, which is slightly higher than our $52 \%$. However, the prevalence is far lower than the study in Gushegu (Also a rural town in Northern Ghana), that showed a prevalence of $76.8 \%$ among pregnant women ${ }^{[12]}$ and results from a study conducted in Bimbilla (Another rural town in Northern Ghana), which yield a prevalence of $75.3 \%$ among pregnant women ${ }^{[13]}$.

Knowledge on anemia in pregnancy was assessed on the basis of knowing the signs/symptoms, causes/risk factors, and preventive measures of anemia in pregnancy. In this study, $69.1 \%$ of the respondents had been educated on anemia in pregnancy, while $30.9 \%$ of the respondents had never been educated on anemia in pregnancy (Table.1.6). Those who were not educated explained that was their first time of antenatal care. Among those that had been educated on anemia in pregnancy, the majority of them received the education during their routine antenatal care visits, while the rest were educated by family and friends.

Our results revealed that there is an association between the respondents' knowledge about anemia in pregnancy and the 
likelihood of them been anemic. (p -value $<0.001$ and 0.001 ). $59.6 \%$ of those educated on anemia were not anemic, whiles $78.6 \%$ of those that had never been educated on anemia in pregnancy were anemic. Concerning knowledge on anemia in pregnancy, $64.7 \%$ of the pregnant participants had poor knowledge on the signs/symptoms of anemia in pregnancy while only $2.9 \%$ had good knowledge, $54.4 \%$ of the pregnant participants had poor knowledge on the causes/ risk factors of anemia in pregnancy while $9.6 \%$ had good knowledge and $49.3 \%$ of the pregnant participants had poor knowledge on the preventive measures of anemia in pregnancy while $22.1 \%$ had good knowledge (Table 1.6). This implies that more targeted educations efforts at the antenatal care unit are needed to help reduce the prevalence of anemia in pregnancy at the district level. This finding however differs from a study conducted in Ethiopia where $71.6 \%$ of the study participants were able to identify the symptoms of anemia, regarding causes, a combined $72.9 \%$ knew the causes of anemia and $57.3 \%$ had good knowledge towards the prevention of anemia in pregnancy ${ }^{[14]}$.

There was a significant association (p-value 0.014) between the occupational status and the anemic status of the pregnant participant, where $74.1 \%$ of housewives and $64.7 \%$ of farmer were anemic and, only $38.5 \%$ of traders and $22.2 \%$ of Government workers were anemic. This is consistent with a study conducted in Gushegu, where $53.4 \%$ of housewives were anemic ${ }^{[12]}$, but not consistent with a study which showed that $33 \%$ of employed pregnant women were anemic as opposed to $39 \%$ unemployed pregnant women who were anemic ${ }^{[15]}$. There was also a significant association ( $p$-value $<0.001$ ) between the educational status and the anemic status of the pregnant participant, where $69.0 \%$ of those without any formal education and $68.4 \%$ of those with only primary level education were anemic, while, $87.5 \%$ of those with vocational level education and $78.9 \%$ of those with tertiary level education were not anemic. This is similar to the study in Gushegu, where $67.4 \%$ of pregnant women who had not received any form of formal education were anemic ${ }^{[12]}$. However, there was no association between anemic status of pregnant participants and age, marital status and religion. This is contrary to the findings from a study in Sekyere West District, Ghana where there was a significant association between age and the anemic status of the pregnant participant, where prevalence of anemia was lower prevalence with increasing age of women ${ }^{[16]}$.

Under the obstetric and antenatal background, only the number of times of iron/folate intake was significantly associated with the anemic status of the study respondents, with a high anemia prevalence of $96.4 \%$ and $80.0 \%$ in pregnant women who took in the iron/folate supplements some days in a week and never taken at all respectively. However, variables such as gravidity, parity, number of antenatal care attendance and whether currently on iron/folate supplement were not significantly associated with the anemic status of the pregnant women. This result somehow does not correspond with a study conducted in Accra, Ghana where parity and number of antenatal care visits where significantly associated with anemia in pregnancy. In the same study, However, gestational age was not significantly associated with anemia in pregnancy ${ }^{[17]}$.

There was an intrinsic association between the anemic status of the pregnant women and sleeping under insecticide treated nets, number of meals taken in day, weekly intake of heme containing meals and weekly intake of tea (p-value $0.027,<0.001$, $<0.001$ respectively). $70.0 \%$ of pregnant women not sleeping under insecticide treated nets were anemic, $87.5 \%$ of pregnant women who ate only twice a day were anemic, $75.0 \%$ and $79.4 \%$ of pregnant women who ate heme containing foods only once and twice a week respectively were anemic, while $100 \%$ and $88.2 \%$ of pregnant women who consumed tea every day and somedays in a week were anemic. This result is different from the findings of a study conducted in the Bolga Regional Hospital, Ghana where there was no significant association between the number of meals taken in a day and the anemic status of the pregnant women ${ }^{[18]}$. Furthermore, a study conducted in Northern Ghana showed that the use of insecticide treated nets and anemia in pregnancy had no significant association as it did not differ among anemic and nonanemic participants; meanwhile sickling status was not significantly associated ( $p$-value $=0.173$ ) with the anemic status of the pregnant women ${ }^{[19]}$. However, sickling status was not significantly associated (p-value 0.173 ) with the anemic status of the pregnant women.

\section{Study Limitations}

Due to the disparities in the gestational ages of our respondents, we could not get the hemoglobin $(\mathrm{Hb})$ levels at 28 and 36 weeks of gestation rather, the current $\mathrm{Hb}$ Level and $\mathrm{Hb}$ level at booking were used for data analysis. Data on the Morphological characteristics of the red blood cells was not available to help identify and classify the types of anemias. Most respondents did not have stool and urine microscopy done to identify Schistosoma species, Entamoeba histolytica, hookworm ova as some of the possible causes of anemia. The sickling status of some respondent was also not readily available for assessment.

Though this study was solely conducted within the West Gonja hospital as it has the highest antenatal visit turnout, the study findings cannot be used to generalize for the entire district. The study methodology did not create a conducive environment for the researchers to follow up on some of the participants who were most likely to experience pregnancy related complications due to their anemic status.

\section{Conclusions}

From our research, the prevalence of anemia among pregnant women attending antenatal care at the West Gonja Hospital was $52.2 \%$. The majority of the expectant mothers claimed to have been educated about the most relevant and common characteristics of anemia in pregnancy. Despite this knowledge, a significant number of the pregnant women exhibited very poor knowledge especially regarding the possible causes, risk factors as well as practical strategies to prevent anemia in pregnancy. And since the knowledge was associated with the anemic status of the pregnant women, most pregnant women who had poor knowledge on the signs/symptoms, causes/risk factors, and preventive measures of anemia in pregnancy were also anemic. The risk factors of anemia in pregnancy identified were unemployment (housewife), low educational status, noncompliance with iron/folate supplementation, not sleeping under insecticide treated nets, eating less than three times a day, eating less than three heme containing meals a week, daily tea consumption everyday whiles pregnant.

\section{Recommendations}

1. The Damongo district health directorate should educate women in the district on the importance of including diets rich in iron and other nutrients to build their iron stores and minimize the risk of developing anemia during pregnancy. More emphasis must also be place on the 
need to avoid or reduce the consumption of tea products during pregnancy.

2. Management of the district hospital should educate the men on the importance of good nutrition during pregnancy and its importance in preventing anemia, so as to make their wives or relatives have access to good nutrition during the pregnancy period.

3. Pregnant women must be encouraged to sleep under insecticides treated mosquito nets

4. The midwives in the district should be well educated on the symptoms and signs of anemia in pregnancy, to enable them educate the pregnant women during antenatal visits, this would help in reporting early to the hospital to prevent any further complications. Also, they must ensure every registrant is given a new insecticide net and educated on how to use it effectively.

5. Ghana Health Service (GHS) should include Preconceptual Care in its policies. This should involve iron and folate supplementation covering all women in fertility age (WIFA) irrespective of their pregnancy status. This would help build up their nutrient stores (especially iron and folate) before they conceive.

\section{Acknowledgement}

The authors of this study want to officially acknowledge the Management Team and Staff of the West Gonja District Hospital, especially all the nurses at the antenatal care unit for all their support and cooperation during the data collection Period.

\section{Declaration of conflict of interest}

The authors have no conflict of interest to declare

\section{Source of funding}

No financial support was received from any public or private institution for the conduct of this research. The activities of this research were conducted using monies from the annual Book and research allowances allocated by the Government of the republic of Ghana to every researcher within the public academic/research Institutions

\section{Data availability Statement}

The processed mixed qualitative/quantitative data that supports the findings and conclusions of this study are readily available through the corresponding author.

\section{Authors Contributions}

The research idea was conceived by MMDM and approved by all authors after putting the research topic through a re-wording exercise. MA conducted the literature review and collected all the relevant data. OR performed the data analysis. The Manuscript was written by MMDM, reviewed by all authors who agreed with its content and made a collective decision to submit for consideration and possible publication

\section{References}

[1] World Prevalence of anemia: WHO database on anemia; WHO Press, Geneva
[2] Macdonald, CS. Anemia- Can its widespread prevalence among women in developing countries be impacted? Anemia in women: A Global health priority; 2002, 1-42

[3] Iron deficiency anemia: Assessment, Prevention and control. A Guide for programme managers. WHO/UNICEF/UN; (2001).

[4] Physiology of Pregnancy: In Merck Manual, (2013)

[5] Balarajan, YR et al. Anemia in low income and middleincome countries. The Lancet 2011; 378(9809): 2123 2135

[6] World prevalence of anemia in pre-school aged children, pregnant women and non-pregnant women of reproductive age. http://www.a2zproject.org/a2zorg

[7] Agan, TE et al. Prevalence of Anemia in women with asymptomatic malaria parasitemia at first antenatal care visit at the University of Calabar teaching hospital, Calabar, Nigeria. International Journal of Women's health 2010; 2(1): 229-233.

[8] De Benoist, BM et al. WHO Global database on anemia: Worldwide prevalence of anemia 1993-2005. Geneva, WHO Press; (2008)

[9] McLean, EE et al. Worldwide Prevalence of anemia, WHO vitamin and mineral nutrition information systems 1993-2005; (2008)

[10] Christian, PC et al. Antenatal and Postnatal Iron. Am J Epidemiol 2009; 170(9): 1127-1136

[11] Masukume, GK et al. Risk factors associated and birth outcomes of anemia in early pregnancy in a nulliparous cohort. SCOPE Consortium, (2015)

[12] Kyei, DY et al. Anemia in pregnancy: Prevalence and risk factors among pregnant women attending antenatal at the Gushegu District Hospital; Ghana, (2018)

[13] Quansah, J. Prevalence and risk factors of anemia among pregnant women at booking at the antenatal care clinic in the Bimbilla Hospital of the Nanumba North District, Northern Region, Ghana.

[14] Kennini, BD et al. Assessment of knowledge and practice towards prevention of anemia among pregnant women attending antenatal care in government hospitals in west shoa zone, Ethiopia. Journal of Health, medicine and Nursing 2018; 31-39

[15] Nduhui, GW et al. Prevalence of anemia among pregnant women attending antenatal clinic at Mbagathi District Hospital; Mbagathi.

[16] Mary-Glover, Amengor; WO et al. Determinants of Anemia in pregnancy in Sekyere West District. Ghana Medical Journal, 102-107

[17] Kwabena Acheampong, SA et al. Prevalence of anemia among pregnant women attending antenatal clinic in a selected Hospital in Accra, Ghana. International Journal of health science and research 2018; 186-193

[18] Ahenkorah, B et al. Biochemical and hematological profiles of anemic pregnant women attending antenatal care at the Bolgatanga Regional Hospital, Upper East Region, Ghana; (2015)

[19] Engelbart, A et al. Descriptive Epidemiology of Anemia among pregnant women initiating antenatal care in rural northern Ghana. African Journal of Primary Health Care and Family Medicine 2007; 1-7

[20] Clerk, BG et al. Epidemiology of Malaria among pregnant women attending antenatal clinics in an area with intense and highly seasonal Malaria transmission in Ghana, (2009). 